\title{
Gaya Bahasa Al-Tawkīd daripada Perspektif Nahu dan Baläghah Arab
}

\author{
${ }^{1}$ BAMBANG MUHAMAD RAFADI YUSOFF \\ ${ }^{2}$ SAINI AG. DAMIT
}

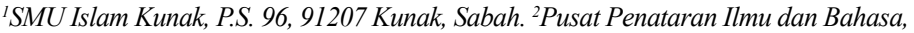
Universiti Malaysia Sabah, Jalan UMS, 88400 Kota Kinabalu, Sabah, Malaysia. Ismu_kunak@yahoo.com, 2saini@ums.edu.my
\end{abstract}

\begin{abstract}
Abstrak Artikel ini membincangkan secara naratif deskriptif elemen alTawkīd dan peranannya dalam bahasa dan primasastera Arab. Perbincangan tentang al-Tawkìd bukan sahaja terhad pada perbahasan dalam ilmu nahu Arab, bahkan merentasi sosiobudaya bangsa Arab itu sendiri yang dijelmakan melalui kewibawaan retorik (baläghah) dan sasteranya (adab). Fungsi dan implikasi al-Tawkìd dalam bahasa dan budaya Arab telah menempatkan gaya bahasa (uslūb) tersebut pada kelasnya yang tersendiri. Hasil perbincangan dalam artikel ini mendapati bahawa bahasa dan budaya Arab bukan sahaja memerihalkan al-Tawkid dalam wacana seharian, tetapi juga menggarap aura keintelektualan dan kecekalan peribadi bangsa Arab di persada kelestarian fizik dan linguistik. Lihat sahaja bagaimana mereka mengungkapkan ketegasan dalam menanggapi sesuatu yang menjadi impian atau tujahan dalam kehidupan seharian; bukan sahaja menerusi tatabahasa al-TawkīdalLafziyy atau al-Ma'nawiyy semata, malah menjangkau elemen-elemen nahu yang lain seperti al-Qasm (sumpah), al-Maf'ūl al-Muțlaq (akusatif melampau), Zarf al-Zamān (kedudukan masa), al-Nidā' (panggilan), alBadal (gantian), al-Na'at (adjektif) dan sebagainya. Demikian juga apabila ditelusuri khazanah sastera yang tersimpan pelbagai jalur dan galur primasastera Arab yang amat menarik dan mengagumkan; antaranya ialah penggunaan gaya bahasa al-Tawkid dalam ungkapanungkapan sasterawan Arab seperti al-Mubālaghah (kepalingan), al-Ițnāb (penghuraian), al-Taqdìm wa al-Ta'khīr dan sebagainya. Justeru, itulah sebabnya mengapa al-Quran al-Karim yang kaya dengan mesej penegasan dan peneguhan tentang ayat-ayat Allah SWT menggunakan gaya bahasa al-Tawkīd versi bahasa dan budaya Arab tersebut yang sekali gus mengangkat martabatnya ke tempat yang paling mulia di dunia dan akhirat.
\end{abstract}


Kata kunci: Gaya bahasa, tawkid, tatabahasa Arab, balaghah Arab

\begin{abstract}
This article expounds narratively the description of al-Tawkid element and its role in Arabic language and prime literature. Discussion concerning al-Tawkìd is not only limited to the debate in Arabic grammatical knowledge; it also crosses the Arabian socioculture itself which is manifested through rhetorical authority (balaghah) and its literature (adab). The function and implication of al-Tawkid in Arabic language and culture have placed the language style (uslüb) in a class of its own. The outcome of discussion in this article found that Arabic language and culture do not only describe al-Tawkìd in daily discourse, but it also undertakes the aura of intellectuality and personal perseverance of the Arab nation in the stage of sustainable physics and linguistics. Look at how they express assertiveness in perceiving a certain thing which becomes an ambition or a thrust in everyday life; not only through grammar al-Tawkidal-Lafziyy or al-Ma'nawiyy alone, yet it extends over other grammatical elements such as al-Qasm (oath), alMaf'ūl al-Muțlaq (extreme accusative), Zarf al-Zamān (Position of Time), al-Nida' (summon), al-Badal (Substitution), al-Na'at (adjective) and so forth. Similarly, when searching through a treasure of literature in which stores various lines and strains of very fascinating and impressive Arabic prime literature; one of them involves the use of language style al-Tawkid in literary expressions by Arabian writers, such as al-Mubālaghah (Hyperbole), al-Ițāb (Elaboration), al-Taqdīm wa al$T a$ 'khìr and et cetera. Hence, it is not surprising that al-Quran al-Karim is rich with messages concerning assertion and reinforcement of the verses of Allah SWT that uses language style al-Tawkid of the version of Arabic language and culture which lifts its prestige at once to the most honorable position in the world and hereafter.
\end{abstract}

Keywords: Language style, tawkïd, Arabic grammar, Arabic balaghah 


\section{PENDAHULUAN}

Konsep al-Tawkid yang mencetuskan gaya bahasa pengukuh dan penguat, sama ada dari sudut lafaz mahupun makna adalah tidak terhad pada perbincangan peraturan tatabahasa sahaja. Ia turut dibahaskan dalam peraturan wacana (baläghah) dan dalam peraturan pembentukan kata (al-Şarf) yang melibatkan ayat-ayat tertentu, yang menunjukkan kekuatan dan kehebatan serta melibatkan sedikit banyak pada bahagian-bahagian yang berfungsi (hurūf al-ma'ān $\bar{\imath}$.

Menurut pandangan ahli Nahu Arab, al-Ta'kīd atau alTawkìd ialah mengukuhkan makna (tashdìd al-ma'nā), iaitu unsur penurut $\left(t \bar{a} b i^{i}\right)$ yang berfungsi sebagai penetap makna yang dituruti (matbu $\left.\bar{u}^{\prime}\right)$ di dalam ayat yang mengandungi uslub al-Tawkìd dan akhirnya tidak ada lagi makna ayat yang perlu diragui. Perkara ini juga ada kaitannya dengan makna-makna fungsi kata (al-ma'ānī ali'rābiyyah). Secara umum, apa yang mereka maksudkan ialah menggunakan beberapa cara khusus untuk menguatkan pertuturan yang terdahulu dan menetapkannya, sama ada dengan teknik melafazkannya sekali lagi (mengulang sebutannya) atau menggunakan perkataan-perkataan khusus untuk menetapkan mesej dan mengelak kekeliruan.

Balāghah Arab pula berpandangan al-Tawkīd amat berkaitan dengan 'ilm al-Ma'ān̄ dan juga dikenali sebagai al-Takrīr (pengulangan). Ia terbahagi kepada dua kategori. Kategori pertama terbahagi kepada dua bahagian, iaitu pertama, pengukuh pada lafaz dan pada makna sekali gus. Kedua, pengukuh pada makna sahaja tidak pada lafaz. Kategori kedua ini terbahagi pula kepada dua bahagian, iaitu; al-mufid (memberi faedah) dan ghayr al-mufid (tidak memberi faedah). Justeru, al-Tawkìd tidak digunakan sewenang-wenangnya melainkan ketika ia diperlukan kerana ia merupakan suatu kenyataan yang dipengaruhi oleh faktor-faktor dan kedudukannya yang tersendiri.

Kajian ini bertujuan untuk menjelaskan secara naratif kewujudan elemen-elemen al-Tawkīd dalam disiplin nahu dan retorik Arab. Selain daripada itu, ia juga bertujuan memperluas skop dan bidang kajian gaya 
bahasa al-Tawkīd yang biasanya hanya dihadkan pada kajian Nahu Arab. Kajian ini mengetengahkan contoh-contoh ayat gaya bahasa alTawkīd yang relevan dengan perbahasannya dalam disiplin Nahu dan Retorik Arab.

Kajian ini menggunakan kaedah kualitatif dengan pendekatan deduktif. Teknik persembahan yang diketengahkan ialah naratifdeskriptif dengan mekanisme pengumpulan data secara kepustakaan. Suatu kesimpulan atau pernyataan umum yang abstrak telah dibentuk terlebih dahulu dan kemudiannya disusuli dengan pembentukan dan penghuraian sub-subtopik atau pernyataan-pernyataan sokongan yang bersifat konkrit bagi menjelaskan dan memperkukuh pernyataan utama. Justeru, kajian ini telah mempersembahkan secara naratif bagaimana suatu kesimpulan abstrak telah ditentukan. Entiti gaya bahasa al-Tawkìd sesungguhnya mempengaruhi elemen-elemen tertentu dalam disiplin nahu dan retorik Arab yang dapat dihuraikan dan diklasifikasikan bersandarkan dalil atau contoh ayat yang relevan dan signifikan dengan sub-subtopik atau kategori-kategori sokongan yang terbentuk kemudian. Kajian ini telah menghasilkan suatu kerangka konsep tentang kajian gaya bahasa al-Tawkìd dalam linguistik Arab melalui persembahan deskriptif seperti yang termuat dalam artikel ini.

\section{GAYA BAHASA $A L-T A W K I D D$ DARIPADA PERSPEKTIF NAHU}

\section{Pengukuh Sebutan}

Pengukuh sebutan (al-tawkīd al-lafžiy) ialah sebutan (lafaz) yang diulang dengannya akan apa-apa yang datang sebelumnya. Jika yang datang sebelumnya itu dalam bentuk lafaz ayat, maka kebanyakannya diiringi dengan al-'attif (dengan perantara partikel 'ațaf) seperti firman Allah

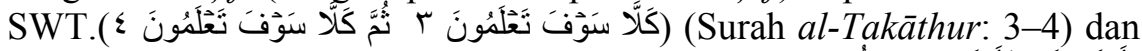

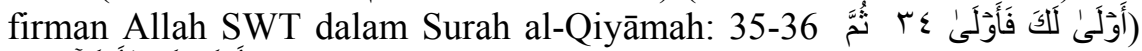

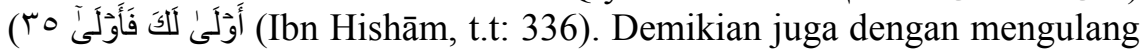
apa-apa yang dikukuhkan dengan sebutannya (yang asal) atau dengan mendatangkan sinonimnya (seperti dengan lafaz tersebut), sama ada yang diulang itu kata nama jelas (ism zăhir), ganti nama (damīr), kata kerja ( $f i^{\prime} l$ ), partikel (harf) mahupun ayat (jumlah) (Muștafā al-Ghalāyiniy,

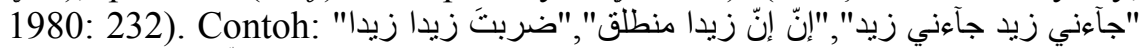
dan "و ما أكرمني إلاّ أنتَّ أنتَّ" (Ibn Ya‘īsh, t.t: 41). Jelasnya, pengukuh sebutan ialah mengulang sebutan pertama dalam bentuknya yang asal 
atau dengan mendatangkan sinonimnya yang merangkumi kata nama jelas, ganti nama, partikel, kata kerja dan ayat (Ahmad al-Hāshimiy, t.t: 286-287). Maksudnya, pengulangan sebutan terdahulu dengan teksnya atau sebutan lain yang seerti dengannya ('Abbās Ḥasan, t.t: 525). 'Abduh al-Rājihìy (1998: 379) merumuskan seperti berikut:

Iaitu pengulangan lafaz unsur yang dikukuhkan (almuakkad) atau dengan apa yang pada maknanya. Dii ' $r a \bar{b}$ pada semua situasinya sebagai pengukuh sebutan yang mengikut unsur yang dikukuhkan pada i'rābnya tanpa sebarang pengaruh pada unsur atau sesuatu yang selepasnya, contohnya: الاجتهاد الاجتهاد طريق النّجاح. Boleh juga mengukuhkan ganti nama yang bersambung yang dinominatifkan dan selainnya secara sebutan (tawkid lafžiy) dengan ganti nama yang terpisah yang dinominatifkan, yang tidak ada baginya tempat daripada al-I'rāb (Là mahalla lahu min al-I'rāb), contohnya: فَّلَّ

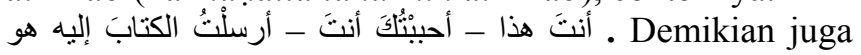
harus mengukuhkan partikel dan kata kerja secara sebutan (lafz̧iy), dan harus juga mengukuhkan ayat dengan menggunakan partikel al-'Atf "thumma" pada kebiasaannya yang bukan maknanya al-'atf.

Sekiranya ia adalah kata nama yang jelas atau ganti nama terpisah yang diakusatifkan, maka hal itu adalah jelas. Sekiranya ganti nama tersebut terpisah yang dinominatifkan, maka boleh dikukuhkan dengannya dengan menggunakan semua ganti nama yang bersambung seperti "قَتَ أنتَ". Sekiranya ganti nama tersebut bersambung, disambungkan dengan apa-apa yang disambungkan dengannya yang dikukuhkan tadi seperti "عجبت منك منك". Jikalau dalam bentuk kata kerja atau partikel yang bersituasi jawapan, maka jelas seperti "قام زيد", namun sekiranya bukan bersituasi jawapan, maka wajib dua perkara. Pertama, kedua-duanya hendaklah dipisahkan. Kedua, hendaklah diulang berserta pengukuh tersebut apa-apa yang bersambung dengan yang dikukuhkan sekiranya ia adalah ganti nama, dan diulang ia atau damīnya

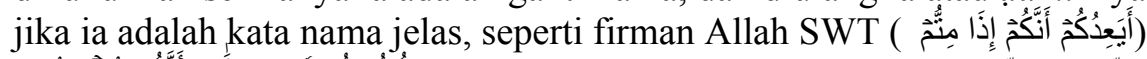

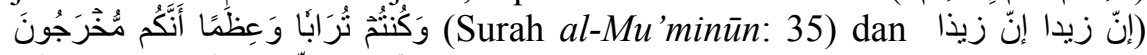

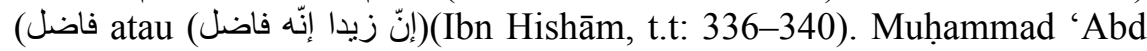
al-Khāliq 'Uḍaymah (1973: 14-19) telah menghuraikan dengan jelas 
cara-cara mengukuhkan ganti nama, kata kerja, jar wa majrūr dan ayat dengan mengambil contoh-contoh dari ayat-ayat al-Quran.

'Abbās Ḥasan (t.t: 526) telah merumuskan beberapa tujuan pengukuhan sebutan, antaranya ialah:

1. Membolehkan pendengar mendapatkan sebutan (lafaz) yang belum pernah didengarnya, atau pernah didengarnya tetapi tidak berapa jelas atau tidak berapa meyakinkan.

2. Sebagai ancaman (al-tahdīd). Contohnya dalam firman Allah SWT (كَلَّل سَوْفَ نَعَلَمُونَ) (Surah alTakāthur: 3-4).

3. Sebagai menyatakan kehebatan (al-tahwīl $)$. Contohnya dalam

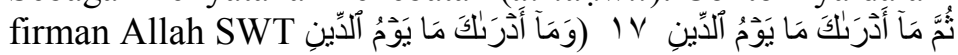
( ^ (Surah al-Infițār: 17-18).

4. Sebagai menyatakan perasaan seronok (al-taladhdhudh).

\section{Pengukuh Makna}

Antara lafaz-lafaz pengukuh makna yang terkenal ialah nafs, 'ayn, kilā, kiltā, kull, jamī' dan 'àmmah. Lafaz-lafaz ini mesti didahului oleh alMuakkad (unsur yang dikukuhkan). Al-Muakkad tersebut hendaklah dalam keadaan ma'rifah, bersamaan dengannya pada al-i'rāb dan diidāfahkan (disandarkan) kepada ganti nama yang kembali kepada almuakkad, contoh: "Jā'a Zaydun nafsuh." (dinominatifkan dengan aldammah), "Ra'aytu Zaydan nafsah." (diakusatifkan dangan al-fathah), dan "Marartu bi Zaydin nafsih" (Digeneratifkan dengan al-kasrah) ('Abd al-Rājị̣iy, 1998: 376).

Kilā dan kiltā digunakan untuk mengukuhkan al-muthannā, contoh: "Haḍara al-ustādhān kilāhumā", "Ra'ytu al-ustādhayn kilayhimā" dan "Marartu bi al-ustādhayn kilayhimā. Bagi mengukuhkan keseluruhan (al-shumūl) pula, lafaz-lafaz kull, jami' dan 'āmmah digunakan, contoh: "Qara'tu al-kitāba kullahu”, "najaha al-mujtahidūn kulluhum”, kāfa'tu al-mujtahidīn kullahum", A'jabtu bi al-lā'ibìn jamī'ihim" dan "Haḍara al-ṭullāb 'àmmatuhum" ("Abd al-Rājihịiy, 1998: 376). 
Terdapat juga lafaz-lafaz lain yang memberi mesej pengukuhan keseluruhan dan biasanya digunakan selepas perkataan kull. Lafaz-lafaz tersebut ialah ajma', jam 'ā', ajma 'ūn dan juma', contoh: "Qara'tu alkitāb kullahu ajma'." (kullahu dan ajma' pengukuh yang diakusatifkan dengan al-fathah al-z̦āhirah), "Qara'tu al-qișsah kullahā jam 'áa" (kullaha dan jam ' $\bar{a}$ ' pengukuh yang diakuastifkan dengan al-fathah alzāhirah), "Hadara al-țullāb kulluhum ajma'ūn." (kulluhum pengukuh yang dinominatifkan dengan al-dammah al-Zhāhirah) dan ajma'ūn pengukuh yang dinominatifkan dengan $w \bar{a} w$ ) dan "Hadarat al-țâlibāt kulluhunn juma'." (kulluhunna dan juma ' pengukuh yang dinominatifkan dengan al-ḍammah al-ẓāhirah) ('Abd al-Rājihịiy, 1998: 377).

Ketika hendak mengukuhkan ganti nama bersambung yang dinominatifkan (al-damīr al-muttașil al-marfī') sama ada ganti nama tersembunyi mahupun terang, maka ia perlu dipisahkan daripada pengukuh dengan ganti nama terpisah yang dinominatifkan (al-damīr alMunfaşil al-Marfü), dan dii 'rāb sebagai pengukuh sebutan (tawkìd lafziy) yang tidak ada tempat baginya daripada al-i 'rāb (La mahall lahā min al-i'rāb), atau dengan menggunakan perkataan lain selain ganti nama. Contohnya "Katabtu anā nafsī hādhà al-mawdī', Fa'alta anta

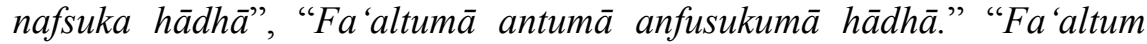
antum anfusukum hädhā". "Fa'altunna antunna anfusukunna hädhā." dan "Darastum - al-sanah al-mādiyah - anfusukum hādhā." Ada pun ganti nama yang tidak dinominatifkan, atau ganti nama terpisah, maka tidak perlu pemisah, seperti "Ra'aytuh nafsah", "Marartu bih nafsih", "Anta nafsuka fa'alta hädhā" dan "Antum anfusukum fa' altum hādhä" ('Abd al-Rājihịiy, 1998: 378-379).

Pengukuh makna ini terbahagi kepada dua, iaitu:

Pertama, yang mengangkat atau menghilangkan keraguan (kesamaran) al-muḍ̄ $f$ kepada yang dikukuhkan. Ia menggunakan dua lafaz (sebutan) iaitu al-nafs dan al-'ayn (Ibn 'Aqīl, t.t: 206-207, Muhammad Khalīl al-Bāshā, t.t: 469). Faedah mengukuhkan sesuatu dengan al-nafs dan al-'ayn ialah menghilangkan kemungkinan bahawa dalam sesuatu pertuturan atau kalām tersebut terdapat unsur majāz, lalai atau lupa (Mușțafā al-Ghalāyiniy, 1981: 233). 
Kedua, yang mengangkat atau menghilangkan keraguan (kesamaran) serta menidakkan kesyumulan (keseluruhan) yang dikehendaki. Ia menggunakan sebutan kull, kilā, kiltā, jamī' dan 'āmmah (Ibn 'Aqīl, t.t: 207).

\section{Kata Nama Terbitan Sebagai Pengukuh 'Āmilnya (Penyebabnya Berfungsi)}

Kata nama terbitan (mașdar) atau penggantinya (nawa 'ib) yang berfungsi sebagai pengukuh 'ámilnya, penjelas kategori atau jenisnya (kualiti) dan penjelas bilangannya (kuantiti). Ia adalah kata nama yang diakusatifkan (ism mansūub) dan dikenali sebagai al-Maf'ūl al-Muțlaq". Justeru, alMaf'ül al-Muțlaq tersebut dikategorikan seperti berikut:

1. Pengukuh faktor penyebabnya ('ämil), contohnya "'Ammara al-muslimūn al-masjid ta 'mīran."

2. Penjelas kualiti (jenis) penyebabnya, contoh "Rahala almust 'mir rahīl al-zalīl.", maknanya "Rahala rahīlan mithl rahịl al-zalīl."

3. Penjelas kuantiti (bilangan) penyebab ('āmil), contoh "Qara'tu al-kitāb qirā'atayn".

\section{Al-Ḥāl (Situasi) Sebagai Pengukuh ‘'Āmil dan Şāḥibnya}

Al-Hāl al-Muakkid (adjektif pengukuh) ialah yang diambil manfaat makna tanpanya ia hanya didatangkan bagi tujuan pengukuhan dan terbahagi kepada tiga (Mușțafā al-Ghalāyiniy, 1980: 93-95).

1. Sebagai peneguh atau pengukuh 'āmilnya (faktor penyebabnya), iaitu yang benar dengannya dari segi makna sahaja, atau makna dan lafaz (sebutan) sekali gus. Contoh yang pertama ialah "tabassama dẹhikā." dan firman Allah

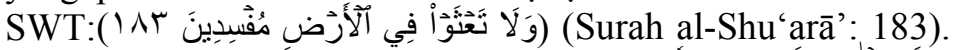

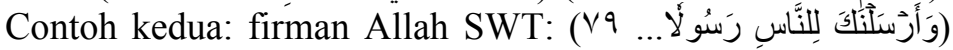
(Surah al-Nisā': 79). 
2. Sebagai pengukuh empunyanya (șāhib). Contoh: "Jā'a alTalāmīdh kulluhum jamī 'an” dan firman Allah SWT: أَفَّنَ)

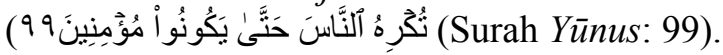

3. Sebagai pengukuh kandungan ayat yang disimpulkan daripada dua kata nama ma rifah lagi jāmid seperti "Hua alhaqq bayyinā aw șarịhā" dan "Nahnnu al-ikhwah muta 'āwinūn".

Dari sudut penjelasan (al-tabyīn) dan pengukuhan ( $\left.a l-t a^{\prime} k \bar{\imath} d\right)$ pula ia terbahagi dua, iaitu:

1. Sebagai penjelas, iaitu kebiasaannya. Dinamakan juga sebagai muassisah (pengasas), iaitu yang menunjuk ke atas satu makna yang tidak difahami dari apa yang sebelumnya.

2. Sebagai pengukuh (al-muakkidah) iaitu yang diambil manfaat maknanya tanpanya (Al-Mațridiy, 1986: 331).

\section{Ganti Nama Al-Fașl (Terpisah)}

Ganti nama ini bukannya ganti nama terpisah (al-damīr al-munfașil), sekalipun ia adalah salah satu jenis ganti nama nominatif (al-raf') yang terpisah. Penamaan sebagai al-faṣl bukan merujuk kepada perkara tersebut, tetapi kerana fungsinya memisahkan antara dua rukun (tonggak) ayat, iaitu memisahkan antara subjek (mubtada') dan predikat (khabar), kata kerja dan $f \bar{a} ' i l$, serta membezakan antara al-Khabar, al-șifah dan alhașrr('Abduh al-Rājihiiy, 1988: 39).

Kadangkala ia berada di tengah-tengah antara al-mubtada' dan al-khabar, atau yang asalnya al-mubtada' dan al-khabar untuk memberitahu bahawa apa yang selepasnya adalah khabar bukannya na'at. Ia memberi faedah kepada pertuturan (kalām) satu bentuk pengukuhan, seperti "Zuhayr huwa al-shā 'ir" dan "Zanantu 'Abdallāh huwa al-kātib.” Damīr al-Fașl ini kedudukannya ialah lā mahallā lah min $a l-i$ 'rāb menurut pandangan yang așah dalam kalangan ahli nahu Arab. Bentuknya adalah bentuk ganti nama-ganti nama al-munfașilah yang lain dan bertașarruf menurut tașarrufnya, hanya ia bukanlah damīr munfașil. 
Tentang faedah-faedahnya pula, Ibn Hishām (1985: 496) telah menyatakan tiga perkara, iaitu:

1. Lafżiy yakni menunjukkan bahawa apa yang terletak selepasnya adalah khabar dan bukannya tābi'. Itulah yang dinamakan faṣl kerana memisahkan antara al-khabar dan altābi' dan dinamakan juga 'imād kerana sangat diperlukan oleh makna pertuturan (kalām). Kebanyakan ahli nahu Arab memberi tumpuan kepada faedah ini.

2. Ma'nawiy iaitu pengukuh. Sesetengah ahli nahu menamakannya dengan du'ämah (penegak) kerana tertegak dengannya kalām. Maksudnya dikukuhkan.

3. Ma'nawiy dalam bab al-ikhtișāṣ. Ia adalah tumpuan kebanyakan ahli al-Bayān.

\section{Al-Badal (Gantian)}

Ia adalah penurut (tābi') yang dimaksudkan dengan mesej (al-hukm). Maksudnya ialah makna pertuturan (al-kalām) tertumpu kepadanya sahaja, di samping itu ia adalah penurut kata nama yang mendahuluinya iaitu al-mubdal minhu (yang digantikan daripadanya). Para ahli nahu Arab menetapkan bahawa al-badal digunakan untuk pengulangan 'àmil (faktor penyebab). Mereka berpandangan, ayat "Käna al-Khalīfah 'Umar 'ādilā", asalnya ialah "Kāna al-Khalīfah Kāna 'Umar 'ädilā." Dalam ayat tersebut, 'āmil tidak dizahirkan pengulangannya sama sekali (mutlak). Al-Badal pula terdiri daripada beberapa kategori seperti berikut (Ibn Hishām, t.t: 440):

1. Al-Badal al-muțābiq atau badal al-Kull min kull, iaitu menggantikan sesuatu dari apa-apa yang bersesuaian maknanya. Contoh: (كان الخليفة عمر عادلا).

2. Badal ba'd min kull iaitu mengganti sebahagian sahaja daripada keseluruhannya sama ada sedikit, sama rata atau lebih banyak. Contoh: (أكلت الرّّغيف ثلثه أو نصفه أو تلثيه). 
3. Badal al-ishtimāl. Tandanya ialah badal dan mubdal minh adalah saling bermuläbasah tanpa perkaitan juzuk. Contoh: (أعجبني زيد علمه).

4. Badal yang berbeza daripada mubdal minhu (yang digantikan). Ia terbahagi kepada dua. Pertama, badal idrāb

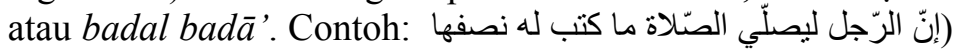
(أن . Kedua, badal nisyān atau badal ghalț. Contoh:

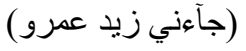

\section{Zarf Al-Zamān (Penunjuk Masa)}

Ia merupakan antara yang berfungsi sebagai pengukuh sesetengah ayat dan kadangkala datang sebagai muassis (pengasas), iaitu memberi makna yang baharu kepada ayat tersebut. Contoh, "Ṣutu shahrä". Perkataan shahr memberi makna yang baharu kepada pendengar kerana perkataan șawm boleh jadi berlaku sehari, seminggu dan sebagainya.

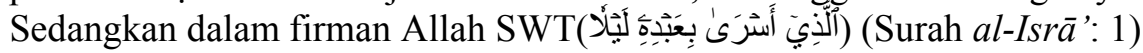
tidak demikian kerana perkataan isrā' sememangnya berlaku pada waktu malam (layl). Justeru, perkataan layl tidak membawa sebarang makna baharu kepada pendengar (al-Mațridiy, 1986: 387).

Antara perkataan yang digunakan sebagai pengukuh dalam zarf al-zamān ini juga ialah qațt, abadā dan 'iwaḍ. Ilyās Dīb (1984: 108-112) menjelaskan seperti berikut:

1. Zarf al-zamān untuk merangkumi masa lampau (istigrāq $m \bar{a}(\bar{\imath})$, biasanya digunakan selepas nafy atau shibhnya. Contoh: (ما ظلمتلك قط).

2. Zarf al-zamān yang datang sebagai pengukuh pada masa depan secara nafy dan ithbät. Contoh: (لا أفعل هذا الأمر أبدا) dan (أفعله أبدا).

3. Zarf al-zamān untuk masa depan dan merangkumi semua yang berlaku pada masa depan. Datang selepas nafy dan

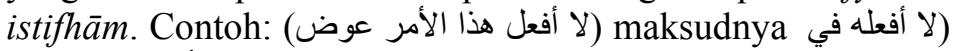
زمن من الأزمنة المستقبلة) 


\section{Al-Na'at (Al-Sifah)}

Al-Na'at (Al-Sifah) terbahagi dua bahagian iaitu pertama, na 'at haqiqqiy (sebenar) dan kedua, na'at sababiy (sebab).

Al-Na'at al-haqīqiy ialah mena'atkan (menyifatkan) kata nama yang mendahuluinya. Ia menurutinya pada semua perkara: al-tadhkir/alta'nīth, al-ta 'rîf/al-tankìr, al-ifräd/al-tathniyah/al-jam' dan pada ali'rāb, contoh: "Najaha al-țālib al-mujtahid", "Najahat al-țâlibah almujtahidah" "Najaha al-țullāb al-mujtahidūn" dan "Najahat al-ṭâlibāt al-mujtahidāt." Kadangkala, na 'at tersebut dalam bentuk kata nama terbitan (mașdar), tetapi dengan beberapa syarat iaitu hendaklah kata kerjanya thuläthiy, bukannya mașdar mìmiy dan mesti sentiasa al-ifrād dan al-tazkìr. Dalam kaitan ini, maka beberapa keadaan berikut perlu diberi perhatian, iaitu;

1. Tidak boleh bersamaan dengan al-man 'ūt (yang disifatkan) melainkan pada al-i'rāb dan al-ta'rîf/al-tankīr sahaja. Contoh: "Hādhā hākkim 'adl" dan "Hāulā' hukkām 'adilun."

2. Sekiranya al-Man 'ūt tersebut jam' muzakkar ghayr 'āqil, maka na 'atnya harus mufrad muannath, jam' muannath sālim atau jam" taksìr muannath. Contoh: "Hādhihī buyūt 'àliyah", "Hādhihī buyūt 'āliyāt" dan "Hādhihī buyūt 'awāl.

3. Sekiranya al-Man 'ūt adalah tamyīz selepas bilangan (11-99), maksudnya mufrad yang diakusatifkan, maka harus na'at tersebut mufrad atau jam! Contoh: "Najaha arba'ata 'ashara țāliban mujtahidan" atau "Najaha arba 'ata 'ashara țāliban mujtahidīn".

Al-Na'at al-Sababiy ialah tidak menyifatkan kata nama yang mendahuluinya dengan bentuk hakiki, tetapi menyifatkan kata nama yang jelas (zahir) yang datang selepasnya dan dinominatifkan dengannya serta merangkumi ganti nama yang kembali kepada kata nama yang sebelumnya. Kata nama yang terakhir inilah yang dinamakan al-Sababiy kerana bersambung (dengan kata nama yang terdahulu dengan "sebab" tertentu seperti kita mengucapkan "Hādha rajul mujtahid ibnuh." 
Terdapat beberapa keadaan al-Na'at al-Sababiy yang perlu diberi perhatian, iaitu:

1. Na'at jenis ini mengikuti man' 'ūtnya pada dua perkara sahaja iaitu al-i'rāb dan al-ta'rîf/al-tankīr. Mengikut kata nama selepasnya pada satu perkara sahaja iaitu al-tadhkir/alta'nīth, contohnya"Hādhā rajul mujtahid ibnuhu." dan "Hādhà rajul mujtahidah ibnatuhu".

2. Jika kata nama yang selepasnya (lāhiqu) adalah mufrad atau muthannā, mesti diifrādkan naa "tnya, contoh: "Hādha rajul ibnuh" dan "Hādhā rajul mujtahid ibnāh." Sekiranya kata nama selepasnya (lāhiqu) adalah jam ' mudhakkar sālim atau jam' muannath sālim, lebih utama (af̣dal) na 'atnya mufrad, contohnya "Hādhā rajul mukhliș muhibbūh" dan "Hādhā rajul mukhliṣah banātuh."

3. Sekiranya kata nama selepasnya (lāhiq) tersebut adalah jam “ taksīr, harus (dibolehkan) na 'atnya mufrad atau jam" sepertinya "Hādhā wațan karìm abnā'uh" dan "Hādha wațan kirām abnā'uh."

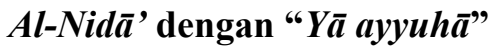

Digunakan ayyuhā (untuk mudhakkar) dan ayyatuhā (muannath) bagi panggilan (nid $\bar{a}$ ') yang melibatkan alif lām. Al-Tathniyah dan al-Jam ' dikekalkan dengan satu sebutan serta diraikan pada kedua-duanya

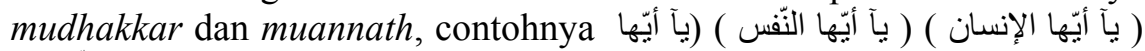
(النّاس. Sekiranya yang menuruti (tābi') tersebut adalah na'at bagi ayyu,

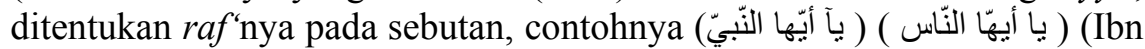
Hishām, t.t: 294-295). Tidak dina 'atkan ayyu melainkan dengan salah satu daripada dua perkara. Pertama, kata nama yang ada alif lām aljinsiyyah seperti (يآ أيّها الإنسان) (يَّان أيّا الرّجل). Kedua, kata nama penunjuk

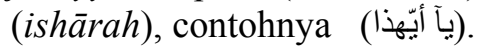

Sesungguhnya gaya bahasa nid $\bar{a}$ ' dengan menggunakan teknik tersebut banyak terdapat dalam al-Quran yang berfungsi sebagai pengukuh dengan cara mengulang sebut (ingat) dan menjelaskan kekaburan. Juga, sebagai pengukuh dengan menggunakan partikel 
al-tanbīh dan pengumpulan dua kata nama yang ma 'rifah (Al-Alūsiy, t.t: 182).

\section{Al-Ikhtiṣāṣ}

Ia adalah kata nama yang diakusatifkan secara al-ikhtiṣās dan dianggap sebagai salah satu jenis al-maf' $\bar{u}$ l bih kerana sebelumnya terdapat kata kerja yang dielipsiskan iaitu akhușsu ('Abduh al-Rājihiiy, 1988: 218) yang daripadanya disempenakan sebutan al-Ikhtișāṣ. Boleh juga ditaqdīrkan dengan kata kerja elipsisa 'nī atau aqșud (Amīl Bad̄̄‘ Ya'qūb, 1986: 22).

Ia diakusatifkan dengan kata kerja elipsis akhușsu selepas ganti nama mutakallim (diri pertama) dan wujud alif lām, contohnya "Naḥnu al-'Arab aqrā al-nās li al-ḍay' dan muḍāf (disandarkan), contoh: "Naḥnu ma 'āshirah al-anbiyā' lā nūrith mā taraknā șadaqah" dan ayyu seperti pada kelaziman nidā' contoh "Anā af'al kadhā ayyuhà al-rajul". Boleh juga diakusatifkan dengan kata kerja ilzam atau ittaq bahawa diulang atau di 'atafkan ke atasnya atau menggunakan iyyāka, contoh "al-Silāh al-Silāh", "al-Akh al-Akh", "al-Sayf wa al-Rumh", "al-Asad al-Asad," "nafsuka nafsuka" dan "Iyyāka wa al-Asad" (Ibn Hishām, t.t: 213).

Tujuan asal al-Ikhtiṣaṣ ialah mengehadkan makna ke atas ism ma'rifah yang membawa mesej pengukuhan makna dan penegasannya ("Abbās Hasan, t.th: 122-124). Bermaksud, al-ikhtiṣāṣ membawa mesej mengukuh dan mengkhusus. Contoh "Nahnnu naz 'umu al-qabīlah" adalah bertujuan kebanggaan, "naḥnu faqīr amām Allāh" bertujuan tawāḍu' dan "Innana nuți' $u$ abawainā" bertujuan penerangan (al-bayān). Sekiranya kita tambahkan pada ayat-ayat di atas dengan gaya bahasa al-ikhtiṣāṣ, contoh: "Nahnnu ma 'shar Quraysh naz 'umu al-qabīlah", "Naḥnu ma shar al-insān naḍ 'af amām Allāh" dan "Innanā ma shar al-Muslimīn nuțī' $u$ abawaină", setiap satunya membawa mesej ta'kīd (pengukuhan) dan tashdīd (penegasan) bagi kebanggaan, kerendahan diri dan penjelasan. 


\section{GAYA BAHASA $A L-T A W K \bar{I} D$ DARIPADA PERSPEKTIF $B A L \bar{A} G H A H \mathrm{ARAB}$}

\section{Al-Majāz Lebih Kebalāghahannya Berbanding Al-Haqūqah}

Al-Haqīqah dari sudut etimologi, berpolakan (wazn) fa' ‘̀l dengan maksud fā 'il, iaitu haqq al-shay'(telah benar sesuatu itu) idhā athbat (apabila telah tetap ia). Atau dengan maksud maf'ül, iaitu haqqaqta al-shay'(anda mentahqiqqakan sesuatu) idha athbattah (apabila anda telah menetapkannya). Kemudian, dipindahkan ke perkataan yang thābit (tetap) atau muthbatah (ditetapkan) pada tempat asalnya. Huruf tō ' yang terdapat padanya adalah sebagai proses perpindahan dari al-wasfiyyah (frasa sifat) ke al-Ismiyyah (frasa kata nama) (Al-Murāghiy, t.t: 254).

Dari sudut terminologi, al-haqīqah ialah perkataan yang digunakan pada tempatnya tanpa sebarang ta'wīl pada peletakannya seperti perkataan al-Asad (singa) dalam bentuknya yang dikhaskan (seekor haiwan yang buas). Maka, lafaz atau sebutan al-Asad tadi diletakkan untuknya dengan al-tahqīq tanpa sebarang ta'wìl padanya. Ia berbeza dengan al-isti'ārah (metafora) yang tidak boleh dinamakan alhaqiqah, tetapi dinamakan majāz lughawiy, lantaran binaan dakwaan perkataan yang dipinjam (al-musta'ār) sebagai yang diletakkan untuk yang dipinjamkan baginya (al-musta 'àr lah) menurut satu jenis daripada penta'wīlan (Al-Sakākiy, 1983: 358).

Ada pun perkataan al-majāz, dari sudut etimologi adalah diambil dari jāz al-shay'(telah melampau oleh sesuatu), idhā ta 'addāh (apabila melanggarinya). Mereka menamakan sesuatu itu dengan lafaz (sebutan) yang dipindahkan daripada makna asalnya dan kemudian digunakan untuk menunjukkan ke atas makna selainnya (bukan makna asalnya) yang sesuai dengannya. Dari sudut terminologi pula, ia didefinisikan sebagai sebutan yang digunakan pada yang bukan selayaknya menurut istilah pertuturan kerana adanya hubungan ('alāqah), iaitu sesuatu yang bersesuaian antara maksud sebenar dengan maksud majāznya. Kadangkala, wujud al-mushābahah antara keduanya dan ada kala tidak. Disertai dengan qarinah (tanda) yang menghalang dari kehendak maksud asalnya, iaitu yang menghalang (māni ${ }^{\top}$ ) dari maksud asal yang kadangkala dalam bentuk lafaz (sebutan) dan ada kalanya dalam bentuk ḥāl (situasi) (Aḥmad al-Hāshimiy, t.t: 290-291). 
Al-Khațīb al-Qazwīniy (t.t: 189) dan al-“Alawiy (t.th: 8-9) menjelaskan bahawa al-majāz lebih kebalāghahannya berbanding alhaqiqah. Al-Mubālaghah tersebut terdapat dalam proses pengithbātan dan pentaqrīran maksud (makna), yang mana penyampaiannya memberi maksud pengukuhan dan penegasan semantik ketika dalam pertuturan. Bermaksud, al-mubālaghah tersebut memiliki ciri-ciri pengukuh, penetap dan penegas yang masing-masing adalah unik.

\section{Jenis-jenis Penyampaian Al-Khabar}

Hak pertuturan disampaikan dengan ukuran atau kadar yang diperlukan oleh maksud yang hendak disampaikan agar tujuan pertuturan tersebut dianggap fasih dan jelas (Ạ̣mad al-Hāshimiy, t.t: 58) supaya menunjukkan ketegasan dan ketetapan. Oleh itu, berbeza-beza bentuk alKhabar di dalam uslüb-uslūb bahasa mengikut pelbagai situasi alMukhāțab yang dapat dikategorikan kepada tiga situasi (Ahmad alHāshimiy, t.t: 58-59):

1. Ibtidā'iy, iaitu al-mukhāțab sunyi mindanya daripada sebarang khabar tanpa keraguan padanya dan tidak memungkirinya. Dalam keadaan sebegini, tidak diperlukan sebarang unsur pengukuhan seperti firman Allah SWT آلَّأن)

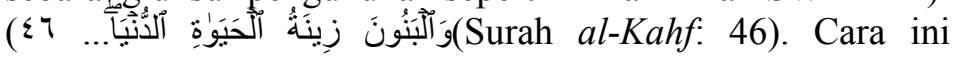
digunakan apabila pendengar tidak merasa sebarang keraguan pada khabar berita yang disampaikan kepadanya.

2. Talabiy, iaitu al-mukhāțab meragui khabar dan terdapat keperluan mengetahui atau mengenali hakikat khabar tersebut. Maka, eloklah dikukuhkan pertuturan atau kalām yang hendak disampaikan tersebut dengan satu alat pengukuh agar dapat meleraikan kesangsian, seperti (إنّ الأمير منتصر). Maksud pengukuhan di sini ialah mengukuhkan hukm (mesej), bukannya mengukuhkan al-musnad ilayh ataupun al-musnad. Cara ini disampaikan apabila pendengar sangsi atau ragu berkenaan sesuatu khabar berita yang disampaikan kepadanya.

3. Inkāriy, iaitu al-mukhāțab memungkiri khabar (berita) yang dibawa atau disampaikan kepadanya dan dia begitu yakin 
kesilapan berlaku pada pihak pembawa khabar (berita) tersebut. Ketika ini, pertuturan hendaklah dikukuhkan dengan sekurang-kurangnya dua alat pengukuh mengikut situasi dan sejauh mana keingkaran pendengar atau penerima khabar

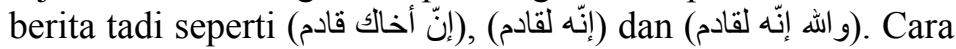
sebegini digunakan sekiranya pendengar atau penerima berita tersebut mengingkari sekeras-kerasnya isi berita yang disampaikan kepadanya.

Ulasannya, gaya bahasa pengukuh digunakan dalam dua jenis penyampaian al-khabar berikut, iaitu al-țalabiy dan al-inkāriy. Fenomena pengukuh di sini jelas menunjukkan telah berperanan penting dalam proses memfasihkan pertuturan dan menzahirkannya. Justeru, kaedahkaedah penyampaian al-khabar kepada al-mukhātab berperanan sebagai penghapus kekaburan, kesangsian dan prasangka dari minda al-mukhätab sehingga pertuturan yang kita tuturkan menjadi lebih jelas dan dapat memuaskan hati para pendengar.

\section{Al-Qaṣr Sebagai Pengukuh dan Pentakhṣīs (Pengkhusus)}

Al-Qaşr dari sudut etimologi ialah sekatan dan tahan. Dari sudut terminologi, ia bermaksud penetapan sesuatu hukum yang disebut pada pertuturan atau penafiannya daripada apa yang selainnya. Atau mentakhșiss suatu perkara dengan suatu perkara lain dengan menggunakan cara atau kaedah yang khusus (dikhaskan untuknya). Definisi yang kedua dianggap lebih menyeluruh kerana merangkumi definisi yang pertama (Muștafāa al-Murāghiy, t.t: 154).

Terdapat dua elemen al-qașr, iaitu al-maqșūr (yang diqașarkan) dan al-maqșūr 'alayh (yang diqașarkan ke atasnya) (Aḥmad al-Hāshimiy, t.t: 179). Contoh, apabila kita katakan (ما سافر إلاّ عليّ), maksudnya ialah mentakhșiṣ al-safar kepada Ali dan menafikan orang lain daripada sesiapa yang disangka bermusafir. Apa-apa yang sebelum illa adalah maqșūr dan apa yang selepasnya adalah maqșūr 'alayh (Muștafā alMurāghiy, t.t: 154). Untuk itu, bagi setiap gaya bahasa al-qașr wujud dua tonggak, iaitu maqșūr dan maqșūr 'alayh (Aḥmad al-Hāshimiy, t.t: 179).

Terdapat beberapa kaedah digunakan untuk tujuan qașr. Antara empat kaedah yang sering digunakan ialah pertama, menggunakan alnafy dan al-istithnā'. Kedua, menggunakan innamā. Ketiga, 
menggunakan partikel 'ațaf seperti lāa, bal dan lākinn. Keempat, menggunakan gaya bahasa mendahulukan yang haknya terkemudian

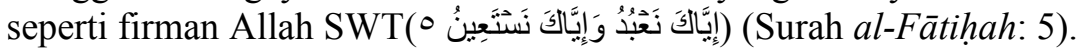

Dari sudut dua rukun atau tonggaknya, al-Qașr terbahagi dua, iaitu (Mușțafā al-Murāghiy, t.t: 185):

1. Qașr sifat ke atas yang disifatkan iaitu ditahan atau disekat sifat ke atas yang disifatkan dan dikhaskan dengannya. Lalu, ia tidak bersifat selain dengan sifat tersebut sahaja kerana ada kalanya al-mawșūf bersifat dengan selain dari sifat tersebut, contoh: (لا لا رازق إلاّ الله) dan( لا زعيم إلاّ سعد).

2. Qașr yang disifatkan ke atas șifah, iaitu ditahan dan disekat al-mawșüf ke atas șifah dan dikhaskan dengannya bukan selainnya kerana ada kalanya șifah-sifah tersebut dikongsi oleh mawṣūf-mawșūf lain contoh: (ما الله إلاّ خالق كلّ شيء).

Dari sudut situasi al-mukhātab, al-qașr terbahagi kepada tiga, iaitu (Mușțafā al-Murāghiy, t.t: 161-162):

1. Qașr ifrād, iaitu apabila al-mukhāțab berkeyakinan wujud perkongsian antara dua perkara atau lebih, contoh: إنّما الله إله (2) واحد yang ditujukan kepada mereka yang berkeyakinan bahawa Allah SWT itu tiga dalam satu dan sebagainya.

2. Qașr qalb, iaitu apabila al-mukhāțab berkeyakinan sebalik hukum ('aks al-hukm) lalu diterbalikkan ke atasnya keyakinannya itu, contoh: (مانشاعر إلاّ شُوقي) sebagai bantahan bagi mereka yang beranggapan atau berkeyakinan bahawa ada penyair yang lebih hebat daripadanya atau ada penyair lain selain Shawqī.

3. Qașr ta'yīn, iaitu apabila al-mukhāțab merasa sangsi pada hukum, contoh: (ما شاعر إلاّ شوقي) bantahan bagi mereka yang merasa sangsi terhadap penetapan al-shāi ' $r$ bagi Shawqī dan bagi sesetengah penyair yang lain. 


\section{Al-Mubālaghah (Berlebih-lebihan)}

Definisi al-Mubālaghah ialah dakwaan bagi penyifatan sampainya sesuatu ke satu tahap atau had yang sangat hebat kuat. Lemahnya juga dianggap tahap yang mustahil dan jauh untuk dicapai sehingga disangka perkara tersebut tidak ada kesudahannya (Al-Khațīb Al-Qazwīniy, 1932: 370).

Al-Mubālaghah terbahagi kepada tiga bahagian. Pertama tablīgh, sekiranya dakwaan tersebut untuk menyifatkan kuat atau lemah sesuatu yang mungkin bagi akal dan kebiasaan (adat). Kedua ighrāq, sekiranya dakwaan tersebut untuk menyifatkan kuat atau lemah sesuatu yang mungkin bagi akal, tetapi tidak pada kebiasaan (adat). Ketiga ghuluw, iaitu sekiranya dakwaan tersebut untuk menyifatkan kuat atau lemah sesuatu yang tidak mungkin atau mustahil bagi akal dan kebiasaan (adat).

Terdapat beberapa pandangan ahli al-Baläghah tentang penerimaan al-mubālaghah. Pertama, penolakan mutlak. Alasan golongan ini ialah bahawa sebaik-baik pertuturan (kalām) adalah yang keluar daripada tempatnya yang benar serta datang dengan cara yang benar juga tanpa menokok tambah. Kedua, penerimaan mutlak. Alasan golongan ini ialah bahawa sebaik-baik syair ialah yang paling dusta antaranya dan pertuturan atau kalām yang paling utama ialah yang dilebih-lebihkan padanya. Ketiga, antara terima dan tolak. Ia merupakan pendapat jumhūr (majoriti) ulama yang menerima baik sekiranya berjalan di atas landasan yang betul kerana di dalam al-Quran juga banyak terdapat unsur al-mubālaghah tersebut datang dalam bentuk yang pelbagai. Golongan ini menolak sekiranya ia datang dalam bentuk al-ighrāq dan al-ghuluw serta mereka menghina penggunanya.

Al-Mubālaghah adalah salah satu ciri pengukuhan dan penegasan melalui pertuturan yang tinggi nilainya. Ketika kita menggambarkan sesuatu dengan cara berlebih-lebihan atau sangat berkurangan, maka terlintas di benak dan fikiran kita, apa yang kita mahukan ialah agar pendengar dapat menghayati betapa seriusnya kita tentang sesuatu yang ingin kita sampaikan. Teknik kita memfokuskannya itu mampu mendatangkan rasa kukuh dan teguh pada kandungan pertuturan kita serta mampu memantapkan tema yang terkandung di dalamnya. 


\section{Pengukuhan dan Pengulangan antara Rahsia al-Iṭnāb}

Al-Ițāb dari sudut etimologi merupakan kata nama terbitan ațab fì kalāmih (berjela-jela pada pertuturannya), apabila dia berlebih-lebih padanya dan memperpanjang ekor-ekornya (Mușțafā al-Murāghiy, t.t: 196) dan melebih-lebihkan serta memperbanyakkan (Al-Mu'jam alWasìt, t.th: 567).

Al-Itnāb dari sudut terminologi pula ialah penambahan lafaz (sebutan) ke atas sesuatu maksud untuk sesuatu keperluan ( $\left.f \bar{a}^{\prime} i d a h\right)$, atau menyampaikan sesuatu maksud dengan ungkapan tambahan melalui kebiasaan ungkapan mereka yang baligh ucapannya untuk sesuatu keperluan memperkuat dan memperkukuhkannya. Contohnya, firman

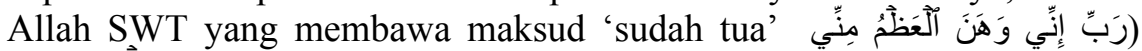

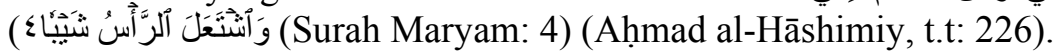

Antara unsur dalam al-ițāab ialah pengulangan (al-takrīr atau altikrār) yang banyak didapati dalam al-Quran dan kalām Arab. Antara fungsinya ialah:

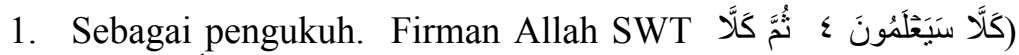

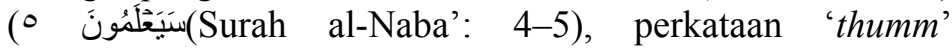
menunjukkan bahawa amaran yang kedua adalah lebih ablagh dan lebih dahsyat (Aḥmad Mațlūb, 1980: 234).

2. Sebagai penambahan perhatian kepada apa yang menafikan keinginan agar sempurna penyampaian kalām dengan

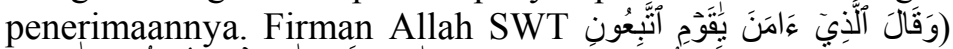

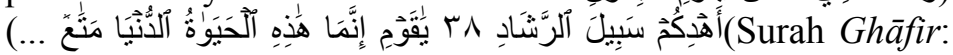
38-39).

3. Sebagai memperbanyakkan yang bersangkutan (almuta'alliq). Allah SWT berulang-ulang menyebut nikmat-

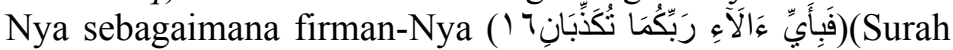
al-Raḥmān: 16). Dalam ayat tersebut, Allah SWT berulangulang menyebut nikmat yang dianugerahkan ke atas makhluk manusia dan jin serta merangsang mereka supaya mengaku kekuasaan dan kelembutan-Nya terhadap mereka (AlZarkāshiy, 1980: 10-11). 
Pengulangan ini ada di antaranya yang berfaedah dan ada juga yang tidak berfaedah. Bagi yang berfaedah, ia dikira sebagai al-ițnāb dan lebih khusus daripadanya. Lalu, disebut bahawa setiap pengulangan membawa faedah al-ițna $b$, namun tidak semua al-ițnāb datang membawa faedah (Darwīsh al-Jundiy, t.t: 208, Mạ̣mūd al-Sayyid Shaykhūn, 1983: 46).

Selain pengulangan (al-tikrār), kita dapati juga ganti nama terpisah berperanan dalam perkara al-ițnāb. Ibn al-Athīr berpendapat, terdapat dua jenis al-ițnāb. Pertama, pengukuhan ganti nama bersambung dengan ganti nama terpisah (mengukuhkan al-damīr al-muttașil dengan menggunakan al-damìr al-munfașil sebagai pengukuh), manakala kedua al-takrīr (mengulang). Ada pun pengukuhan ganti nama bersambung dengan ganti nama terpisah sebagai pengukuhnya, seperti dalam firman

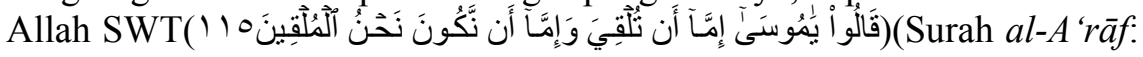
115). Dalam ayat tersebut, mereka yakni ahli sihir mengungkapkan نحن (الملقين) dan tidak menggunakan ungkapan (و إمّا أن نلقي), disebabkan keinginan ahli-ahli sihir tersebut melontarkan terlebih dahulu tongkattongkat mereka sebelum Musa a.s. melakukannya. Maka, didatangkanlah satu ganti nama (al-damìr) yang dikukuhkan dengan menggunakan ganti nama terpisah (al-munfașil) (Aḥmad Mațlūb, 1986: 9).

Antara tujuan dan rahsia pengulangan ialah pengukuhan. Pengulangan tersebut kadangkala berperanan sebagai pengukuhan pada lafaz (sebutan) dan makna sekali gus, kadangkala bergantung juga pada makna sahaja tanpa sebutan. Contoh yang pertama, iaitu pada lafaz dan

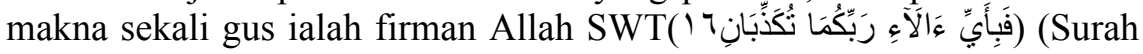
al-Rahmmān: 16), yang diulang beberapa kali secara lafaz dan makna bagi menetapkan perakuan (al-taqrïr) segala nikmat dan mengagungkan perihal keadaannya (nikmat tersebut ). Contoh pada makna sahaja seperti

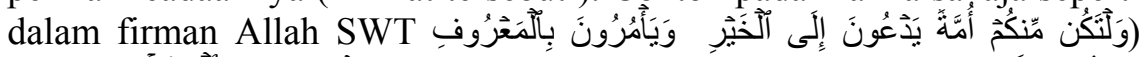

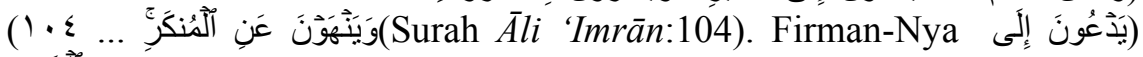
(الخَخِرِ adalah bersifat umum dan merangkumi semua perkara kebaikan, namun sesungguhnya diulang suruhan melaksanakan kemakrufan dan menegah kemungkaran adalah dari sudut pengukuhan dan al-mubālaghah (berlebih-lebihan) (Al-'Alawiy, t.th: 177-190). 


\section{Pengukuhan Secara Al-Taqdīm (Mendahulukan)}

Lafaz-lafaz dalam ayat-ayat bahasa Arab memiliki susunan (sintaksis) yang tersendiri. Al-mubtada' kedudukannya sebelum al-khabar, al-fi 'l sebelum al-fā'il, al-fā'il sebelum al-maf'ül bih, al-jarr dan al-majrūr serta qayd-qayd dan penyempurna-penyempurna lainnya. Namun, susunan tersebut bukanlah mutlak, bahkan boleh berubah mengikut keperluan tatabahasa dan bayāniy (balāghah).

Tujuan-tujuan pentaqdiman, antaranya ialah pertama, mengqașrkan al-musnad ke atas al-musnad ilayh dengan menta 'rïfkan almusnad (alif lām) serta mendahulukannya sebagai tambahan pada maksud pengukuhan, contoh: "الظّالم أنتَّ" ". Kedua, mentakhṣiṣs, menghaṣr dan menta'kìd dengan cara mendahulukan al-fuḍlah ke atas al-'umdah,

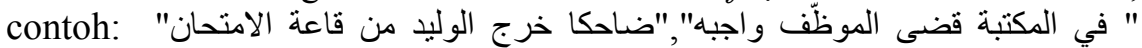
dan"في ساحة المعركة خرّ القآئد صريعان" (Ilyās Dīb, 1984: 66-67). Ketiga, memperkuat al-hukm (mesej) dan mentaqrīrkannya (perakui), contoh: " "هو يعطي الجزيل Pengulangan ganti nama tersembunyi (mustatir) "huwa" pada kata kerja " $y u$ ' $t \vec{\imath}$ ' mentaqrīrkan dalam minda pendengar dan mentahqiq kan bahawa yang melakukan "pemberian yang besar" tersebut adalah "huwa." Maka, mendahulukan "huwa" (al-musnad ilayh) dalam ayat tersebut membawa kepada pengukuhan al-hukm (mesej) dan mentaqrīrkannya ('Abd al-'Azīz 'Atīq, 1985: 152).

\section{Mengukuhkan Pujian dengan Sesuatu yang Menyerupai Hinaan dan Sebaliknya}

Mengukuhkan pujian dengan sesuatu yang menyerupai hinaan dan sebaliknya adalah antara keindahan-keindahan makna dalam ilm al$B a d \bar{l}^{\prime}$. Menguatkan pujian dengan sesuatu yang menyerupai hinaan didatangkan dalam tiga bentuk, iaitu:

Pertama, bahawa dikecualikan sifat pujian dari sifat hinaan yang ternafi daripada sesuatu, dengan andaian (taqdìr) bahawa sifat pujian tersebut masuk pada sesuatu yang dinafikan dalam sifat hinaan tadi. Contoh:

1. Berkata Ibn Nabātah: ولا عيب فيه غيرَ أنّي قصدته * فأنستني الأيّامُ أهلا وموطنا 
2. Berkata al-Nābighah al-Zubyāniy: * ولا عيبَ فيهم غيرَ أنّ سيوفهم بهن فلولّ من قرا الكتائب

3. Berkata penyair lain: تعدُّ ذنوبي عند قوم كثيرةَ * ولا ذنبَ لي إلاّ العلان و الفضائل

Kedua, ditetapkan bagi sesuatu sifat pujian, dan didatangkan selepasnya dengan perantara instrumen pengecualian (istithn $\bar{a}^{\prime}$ ) yang diiringi oleh sifat pujian yang lain. Contoh:

1. Sabda Rasulullah SAW: أنا آفصح العرب، بيدَ أني من قريش إنها

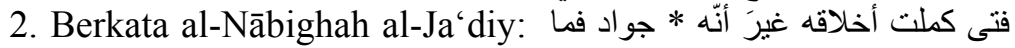
يبقي من المال باقيا

3. Berkata penyair lain: وجوه كأز هار الرّياض نضارة * و لكنّها يوم الهياج صخور

Ketiga, didatangkan dengan yang dikeluarkan padanya akan makna pujian sebagai $m a$ ' $m \bar{u} l$ bagi kata kerja $\left(f{ }^{\prime} l\right)$ yang ternafi padanya akan makna hinaan, yang demikian itu menggunakan gaya bahasa (uslūb) al-istithnā' al-mufarragh. Contoh: Firman Allah SWT dalam

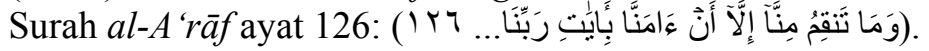

Ada pun mengukuhkan hinaan dengan sesuatu yang menyerupai pujian, maka ia datang dalam dua bentuk, iaitu: pertama, bahawa dikecualikan sifat hinaan dari sifat pujian yang ternafi daripada sesuatu, dengan andaian (taqdīr) bahawa sifat hinaan tersebut masuk pada sesuatu yang dinafikan pada sifat pujian tadi. Contohnya, berkata penyair:

$$
\text { خلا من الفضل غيرَ أني * أراه في الحمق لا يجارَى }
$$

Maksudnya: Tidak ada sebarang kebaikan pada suatu bangsa tersebut, melainkan bahawa mereka berjiran dengan yang hina.

Kedua, ditetapkan bagi sesuatu sifat hina dan didatangkan selepasnya melalui instrumen istithn $\bar{a}$ ' yang diiringi dengan sifat hinaan yang lain. Contohnya, berkata penyair:

$$
\text { لئيم الطباع سوى أنه * جبانٌ يهون عليه الهوانُ }
$$

Maksudnya: Orang yang jahil itu adalah musuh dirinya sendiri, namun dia adalah rakan si dungu. 
Bentuk pertama dari kedua-dua bahagian di atas, dan bentuk ketiga dari bahagian yang pertama adalah lebih kuat dalam menghasilkan pengukuhan. Perkara ini ditinjau dari dua sudut, pertama, pengukuhan padanya menyerupai dakwaan yang mempunyai keterangan (bukti). Seolah-olah orang yang memuji itu beristidlāl (membuktikan) di atas penafian sifat yang hina dengan mengaitkan kewujudannya di atas perkara yang mustahil. Sesuatu yang dikaitkan dengan perkara yang mustahil adalah juga mustahil sifatnya.

Kedua, asal pada pengecualian (al-istithnā') adalah secara mutlak bersambung (mutțașil). Disebut instrumennya sebelum menyebut apa-apa yang selepasnya adalah sangkaan mengeluarkan al-mustathnā daripada al-mustathnā minh. Maka, apabila datang sifat pujian atau sifat hinaan selepas instrumen tersebut serta berubah al-istithn $\bar{a}$ ' tersebut dari bersambung (al-ittișa $\bar{l}$ ) kepada terpisah (al-inqița $)$ ). Justeru, itu adalah pujian di atas pujian, atau hinaan di atas hinaan. Dari sinilah timbulnya aura 'pengukuhan' (al-Tawkīd). Selain daripada itu, aura pengukuhan ini hanya dapat dihasilkan dari sudut yang kedua ini sahaja (Muhammad Muḥammad Khalīfah dan 'Abd al-Ḥakī Ḥasan Na'nā', 2011: 174-180).

\section{KESIMPULAN}

Daripada penjelasan di atas, dapat dirumuskan bahawa penggunaan al-Tawkīd adalah bertujuan untuk menguatkan dan mengukuhkan makna sesuatu ungkapan atau gaya bahasa Arab yang menunjukkan penegasan. Kepelbagaian gaya bahasa atau uslub dalam menterjemahkan mesej penegasan dan pengukuhan tersebut bukan sahaja dicanai daripada unsur-unsur sintaksis atau nahu Arab seperti al-Tawkid al-Lafżiyy, alMa 'nawiyy dan sebagainya. Bahkan, ia digarap juga melalui primasastera Arab yang membentuk sastera dan budayanya yang unik dan tersendiri. Jelasnya, aura al-Tawkīd pada hakikatnya berada di kelasnya tersendiri pada posisi dan tradisi bangsa Arab yang diekspresikan melalui ungkapan-ungkapan dinamik dan bertenaga. 


\section{RUJUKAN}

Al-Quran Al-Karim.

'Abbās Hasan, (t.t). Al-Naḥw al-Wāfì (Cetakan kelima). Egypt: Dār al-Ma' ārif.

'Abd al-'Azīz 'Atīq. (1985). 'Ilm al-Ma' ānī. Beirut: Dār al-Nahḍah al'Arabiyyah.

'Abduh al-Rājihịy (1988). Al-Tațbīq al-Naḥwiy. Beirut: Dār al-Nahḍah al'Arabiyyah.

'Abduh al-Rājiḥiy. (1988). Durūs fì Shurūḥ al-Alīfiyyah. Iskandariyyah: Dār alMa' rifah al-Jāmi' iyyah.

Aḥmad al-Hāshimiy. (t.t). Jawāhir al-Balāghah fì al-Ma' ān̄̄ wa al-Bayān wa alBad̄̄' (Cetakan kedua belas). Beirut: Mu'assah 'Abd al-Hafĩz al-Bassāṭ.

Aḥmad al-Hāshimiy. (t.t). Al-Qawā' id al-Asāsiyyah li al-Lughah al-'Arabiyyah. Beirut: Dār al-Kutub al-'Ilmiyyah.

Aḥmad Mațlūb. (1986). Mu' jam al-Mușțalaḥāt al-Balāgiyyah wa Tațawwaruhā (Cetakan pertama). Baghdād: Maṭba' ah al-Majma' al-'Ilmiy al-'Irāqiy.

Aḥmad Maṭlūb. (1980). Asālīb Balāghiyyah (al-Faṣāhah-al-Balāghah-al-Ma' ānī) (Cetakan pertama). Kuwait: Wakālah al-Mațbū' āt.

Al-'Alawiy, Yahyā Ibn Hamzah Ibn 'Aliy Ibn Ibrāhīm. (t.t). Al-Țirāa al-Mutaḍammin li Asrār al-Balāghah wa 'Ulūm Haqā'iq al-I' jāz. Beirut: Dār al-Kutub al'Ilmiyyah.

Al-Alūsiy, Abū al-Faḍl Shahāb al-Dīn al-Sayyid Maḥmūd. (t.t). Rūḥ al-Ma' ānī fì Tafsìr al-Qur'ān al- 'Azīm wa al-Sab' al-Mathānī. Beirut: Dār Ihyyā' al-Turāth al-‘Arabiy. Tafsīr al-Kitāb al-‘Az̄̄z, Editor: al-Majlis al-'Ilmiy bi Fās.

Al-Ghalāyiniy, Mușțafā. (1980). Jāmi ‘ al-Durūs al- 'Arabiyyah. Beirut: al-Maktabah al- 'Așriyyah.

Al-Khațīb al-Qazwīniy. (t.t). Al-Ị̄̂̄ạ fì 'Ulūm al-Balāghah: al-Ma' ānī-al-Bayānal-Bad̄̄' Mukhtașar Talkhīs al-Miftāḥ, Beirut: Dār al-Jayl.

Al-Khāțīb al-Qazwīniy. (1932). Al-Talkhīş fì 'Ulūm al-Balāghah. (Cetakan kedua). Dlm. 'Abd al-Raḥmān al-Barqūqī (Ed.). Beirut: Dār al-Kitāb al-‘Arabiy.

Al-Mațridiy, 'Abd al-Raḥmān. (1986). Asālīb al-Tawkīd fì al-Qur'ān al-Karīm (Cetakan pertama). Tripoli: al-Dār al-Jamāhiriyyah.

Al-Mu'jam al-Wasīṭ. (t.t). Al-Qāhirah: Dār 'umrān.

Al-Murāghiy, Aḥmad Mușțafā. (t.t.) 'Ulūm al-Balāghah: al-Bayān-al-Ma' ānī-alBad̄̄'. (Cetakan kelima). Al-Maktabah al-Mạ̣mūdiyyah al-Tijāriyyah.

Al-Sakākiy, Abū Ya' qūb Yūsuf Ibn Abī Bakr Muḥmmad Ibn 'Aliy. (1983). Miftāh al-'Ulūm. (Cetakan pertama). Dlm. Na' īm Zarzūr (Ed.). Beirut: Dār alKutub al-'Ilmiyyah.

Al-Zarkāshiy. (1980). Al-Burhān fì 'Ulūm al-Qur'ān (Cetakan ketiga). Dlm. Muḥammad Abū al-Fạ̣l Ibrāhīm (Ed.). Beirut: Dār al-Fikr.

Amīl Badī' Ya' qūb. (1986). Mawsū' ah al-Naḥw wa al-Sarf wa al-I' rāb (Cetakan pertama). Beirut: Dār al-'Ilm li Malāyīn. 
Amīl Badī' Ya' qūb. (1988). Mawsū' ah al-Hurūf fì al-Lughah al-'Arabiyyah (Cetakan pertama) Beirut: Dār al-Jayl.

Darwīsh al-Jundiy. (t.t). 'Ilm al-Ma' ānī. Kaherah: Dār Nahḍah Miṣr al-Fujjālah. Ibn Hishām al-Anșāriy. (t.t). Awḍaḥ al-Masālik ilā Alfiyyah Ibn Mālik. Beirut: Dār al-Fikr.

Ibn Hishām al-Anșāiy. (t.t). Sharḥ Shudhūr al-dhahab fì Ma' rifah Kalām al- 'Arab. Dlm. Muḥammad Muḥȳ̄ al-Dīn 'Abd al-Ḥamīd (Ed.). Beirut: al-Maktabah al-' Așriyyah.

Ibn Hishām al-Anșāiy. (t.t). Sharḥ Quṭr al-Nadā wa Ball al-Ṣudā. Dlm. Muḥammad Muhȳī al-Dīn 'Abd al-Hamīd (Ed.). Beirut: al-Maktabah al-'Așriyyah.

Ibn Hishām al-Anșāiy. (1985). Mughnī al-Labīb'an Kutub al-A' ārib. (Cetakan keenam). Dlm. Dr. Māzin al-Mubārak \& Muḥammad 'Aliy Hamd Allāh (Ed.). Beirut: Dār al-Fikr.

Ibn Ya' ̄̄sh, Muwaffaq al-Dīn. (t.t). Sharh al-Mufașşal. Beirut: 'Ālam al-Kutub. Ilyās Dīb. (1984). Asālīb al-Ta'kīd fi al-Lughah al-'Arabiyyah (Cetakan pertama). Beirut: Dār al-Fikr al-Lubnāniy.

Maḥmūd al-Sayyid Shaykhūn. (1983). Asrār al-Tikrār fì Lughah al-Qur'ān (Cetakan pertama). Kaherah: Maktabah al-Kulliyyāt al-Azhariyyah.

Muhammad 'Abd al-Khāliq 'Uḍaymah. (1973). Dirāsāt li Uslūb al-Qur'ān alKarìm (Cetakan pertama). Mesir: Mațba'ah al-Sa' ādah.

Muhammad Khalīl al-Bāshā. (t.t). Al-Tazkirah fì Qawā'd al-Lughah al- 'Arabiyyah. Beirut: 'Ālam al-Kutub.

Muḥammad Muḥammad Khalīfah \& 'Abd al-Hakīm Hasan Na' nā. (2011.) Miftāh al-Balāghah (Buku Teks STAM) (Cetakan Kedua). Kuala Lumpur: Kementerian Pelajaran Malaysia \& al-Azhar al-Sharīf. 